\title{
Research on the Effect of Basic P.E. Course on the Entire Teaching Effect of Physical Education
}

\author{
Lijun Peng \\ Ji'an College, Ji'an, 343000
}

Keywords: Basic P.E. course, Teaching mode, Improvement

\begin{abstract}
The basic theory knowledge of physical education is the basis of physical practice curriculum, and provides rich theoretical guidance for students' physical training. But in the current school physical education, excessive attention has been paid to the practice teaching of physical education curriculum. The students lack interest in the theory of physical education, and the theoretical courses are less. Seriously ignored the importance of teaching sports theory and the guiding significance of sports practice. Therefore, the school ignores the basic theoretical knowledge of sports. Improving the importance of physical education teachers on the teaching of physical theory knowledge. Strengthen the theoretical knowledge and professional accomplishment of Physical Education Teachers. In view of the current understanding of sports basic courses and the problems existing in teaching, this paper makes a new survey on the teaching operation of physical basic courses by means of questionnaire survey and literature investigation. The teaching mode of physical basic course has a positive influence on the whole teaching effect of physical education.
\end{abstract}

\section{Introduction}

With the continuous reform of the educational system, physical education has also paid more and more attention to students' practical exercise ability. The tendency of physical education to emphasize practice has become more and more serious in the school physical education curriculum, which leads to the students' loss of interest in the basic theoretical knowledge of physical education. In the practice course of physical education, there is no basic theoretical knowledge to guide, which leads to the phenomenon that the training movement is not in place. In the school sports, basic theory curriculum arranged fewer classes, and some schools put the basic theory of physical knowledge discarded, resulting in the sports curriculum difficult to meet the needs of students for sports knowledge. Therefore, in view of a series of phenomena in the basic knowledge of school physical education, we should reform the teaching methods of basic knowledge of physical education in school. Teachers should pay more attention to the basic knowledge of physical education, strengthen their awareness of sports, and pave the way for physical education. The basic sports in the reform and innovation as the driving force of the information age. In the new century in the process, with the change of global science turn the world upside down, the information technology, the digital technology, economic integration, political multi polarization and cultural diversity is the basic trend of the development of the international community, but also reflects the development trend of the society in twenty-first Century.

\section{Problems in Basic Education}

At present, many schools comply with the requirements of the reform of physical education, and have abandoned the teaching of sports basic courses. The curriculum model of PE optional course is set up in the first year of students entering university. Most of the selected projects are mainly interesting and entertaining projects, which pay attention to the students' needs, and promote the development of students' personality and interest. However, there are still some problems in practical teaching.

For a long time, people's understanding of school physical education is in a misunderstanding, coupled with the impact of examination oriented education, the freshmen who enter the University have a serious lack of basic knowledge of physical education, and have little knowledge of physical 
education. Students in the choice of a certain degree of blindness, it is difficult to choose their own sports.

Because of excessive emphasis on students' physical exercise theory and methods, as well as students' sports habits and awareness training, and give up the students' physical quality improvement. The school physical education teaching process is in the student various aspects, the physical fitness development best period, during this period, the student various aspects quality obtains the exercise and the development.

In order to cultivate students interest, some interesting. As the recreational items are fully enriched in the content of physical education, what students learn does not produce much effect on physical exercise, and physical education loses its fundamental significance. Sports itself is a physical ability to exercise people in all aspects of the quality of the will of the people; Everyone has his inertia, especially children. In the sports teaching if students focus on pure feeling, some exercise is not strong project is difficult to achieve the best effect of exercise. Physical education according to the effect of physical exercise combined with students interested in the form of teaching, should achieve better results.

\section{Development Trend of China's Physical Education}

Teaching Objectives are More Diversified. The sports teaching goal is to take the evaluation preparation and teaching quality as the foundation, content and method of teaching play the role of the guidelines. At the present stage, the teaching process of physical education in China is based on the sports theory curriculum. The guiding ideology is the idea of lifelong physical education, which can help students experience the fun when they are engaged in various sports activities, and the teaching content chosen by teachers should be adapted to the needs of students. The teaching of physical education in our country is developing in a pluralistic way, which is based on the improvement of physical fitness and healthy sports. In keeping with students' individuality, PE teaching should also pay attention to train students' team spirit and moral mission, stimulate their creativity, and promote them to have various cultural accomplishment.

Teaching Contents are More Abundant and Diversified. At this stage, the sports programs and types have shown a diversified development trend, the University set up the teaching content of physical education. This is a true reflection of the guiding ideology of physical education and the actual situation of physical education teachers and facilities. In our campus, more and more types of physical education, and the students' physical quality and psychological quality are the differences, and the school is on the basis of a different nature sport. Students also have more choice, the content of sports teaching is more abundant, students can choose to participate in a variety of sports.

The Basic Organizing Forms of Sports Teaching Has Changed. The organizational form of physical education has also changed. First of all, the number of students in the teaching class is increasing, and the increase of the number of students will affect the quality and safety of teaching. Therefore, the number of teaching classes in our country is clearly defined, it is recommended for about 30 people. However, due to the limited number of teaching facilities and physical education teachers, it is necessary to carry out large class teaching.

\section{Suggestions to Innovate Basic Physical Education}

Innovate the Teaching Concept of College Physical Education. In order to ensure the effectiveness of college physical education, it is necessary to innovate and perfect the concept and mode of college physical education. First, we should improve the guiding ideology of college physical education, and we should make clear the teaching idea of "student centered" and "student's health" as the goal. According to the actual situation of college students and their own characteristics, give them enough humanistic care, and take the modern healthy sports teaching idea as the guideline, and make the subject of sports become the internal demand of each student.

Take P.E. as an Academic Course. It is beneficial to the cultivation of students' Sports consciousness. Physical education is a material foundation for students' current growth and their future work and life. Without a healthy body will not have a bright future. Basic education is the stage to lay the foundation for lifelong physical education, and the habit, ability and consciousness of physical education should begin at the stage of basic education. Lifelong sports is not only a kind of consciousness and habit, but also not only for a healthy and civilized life, but also for physical 
exercise as the material basis for physical exercise. Therefore, in the basic education stage, it is very important for students to have lifelong physical education to pay attention to the health of students and to strengthen the study of basic sports culture, basic skills and basic skills.

Optimize the Curriculum Setting and Make the Teaching Contents Closer to Students' Actual Life. This paper summarizes the disadvantages and problems existing in the sports curriculum set up in the past, and summarizes the places that can be drawn and used for reference. With the continuous optimization of the curriculum setting of multimedia teaching means more advanced, the innovation of the existing sports teaching content and form, select more vivid and interesting teaching materials, so as to stimulate students' interest in learning, to adapt to the individual differences between students. In setting up the teaching course of college physical education, we should give full consideration to the psychological needs of modern college students and the general rules of physical education in Colleges and universities, so as to further improve their enthusiasm and initiative in their study. Only in this way can we guarantee the effectiveness of College PE teaching.

\section{Conclusion}

The basic course of college physical education should be based on the development of the students' physiology and psychology at the present stage, and give the students maximum autonomy, giving full play to the students' subjectivity and the leading role of the teachers. So that students have greater room for development and flexibility in learning. In the content arrangement, we should take into account the students' physical exercises in the future and the effect of exercise and other factors, the experiment proved to be practical and effective. In the basic course of physical education, we should make the students more fully. More extensive understanding and familiar with physical training items, accumulate their own sports knowledge, avoid further study and exercise blindly use inappropriate sports methods. In order to be able to according to their own various aspects of the scientific and reasonable choice for their own training items and methods.

\section{References}

[1] Silva D D O, Pizani J, Mendes E H, et al. The subjects rhythmic and danceable in physical education courses in licentiate in the state of Paraná.[J]. Pensar A Prática, 2015.

[2] Wang X, University N X. The Experimental Research on the Development of Early Physical Education for the Children's Basic Movement[J]. Contemporary Sports Technology, 2015.

[3] Salimin N, Shahril M I, Jani J, et al. Development Assessment Instrument for Basic Skills of Invasion in Physical Education[J]. Advanced Science Letters, 2017.

[4] Méndez-Alonso D, Méndez-Giménez A, Fernández-Río J. Integrating the basic competences into physical education in primary education[J]. 2015, 61(61).

[5] Santurio J I M, Fernandez-Rio J. Spanish Version of the Basic Psychological Needs in Physical Education Scale[J]. 2016.

[6] Liu J I, Yin X, Yin Z, et al. Comment on the Learning Guidance Outline of Physical Education in Japanese Basic Education[J]. Journal of Chengdu Sport University, 2015.

[7] Metwaly D. The effects of multimedia computer assisted instruction on learning the swimming basic skills for physical education students.[J]. 2016.

[8] Abel C. Sheriff's Office Gains Funds with Contract[J]. Analysis of Cosmetic Products, 2016, 29(47):3-8.

[9] Yin R B, Ji L. The realistic demands and paths for reforming the contents of physical education curriculum in basic education.[J]. Journal of Physical Education, 2015.

[10] Vorotilkin I M, Anokhina O V, Galitsyn S V, et al. Gender Approach at Physical Culture Lessons at the Second Stage of Basic High Education.[J]. International Journal of Environmental \& Science Education, 2016, 11. 
[11]Herrmann C, Gerlach E, Seelig H. Development and Validation of a Test Instrument for the Assessment of Basic Motor Competencies in Primary School[J]. Measurement in Physical Education \& Exercise Science, 2015, 19(2):80-90.

[12]Pizani J, Araújo M A D, Braguin C, et al. The subjects in gymnastic courses degree in physical education Paraná State.[J]. Conexões Revista Da Faculdade De Educação Física Da Unicamp, 2015. 